\title{
Influence of valproate on the required dose of propofol for anesthesia during electroconvulsive therapy of bipolar affective disorder patients
}

This article was published in the following Dove Press journal:

Neuropsychiatric Disease and Treatment

4 March 2014

Number of times this article has been viewed

\section{Gökben Hızlı Sayar \\ Gül Eryılmaz \\ Siban Șemieoğlu \\ Eylem Özten \\ Ișıl Göğcegöz Gül}

Uskudar University, Neuropsychiatry Istanbul Hospital, Istanbul, Turkey
Correspondence: Gökben Hızlı Sayar Department of Psychiatry, Uskudar University, Neuropsychiatry Istanbul Hospital, Alemdag Caddesi Site Yolu No 29, Umraniye, Istanbul, Turkey

Tel +902166330649

Fax +90 216 634 I250

Email gokben.hizlisayar@uskudar.edu.tr
Background: Propofol is often used as an anesthetic agent for electroconvulsive therapy (ECT). In recent studies, propofol was shown to possess significant seizure-shortening properties during ECT. "Valproate" is a mood stabilizer used mainly in the treatment of bipolar affective disorder. It is reported that valproate, being an anticonvulsant, raises the seizure threshold, thus decreases the efficacy of ECT treatment.

Aim: The purpose of our study was to compare the dose of propofol in valproate-using patients and valproate-free patients.

Methods: In an open design, 17 patients with bipolar affective disorder manic episodes who were to be treated with valproate and ECT in combination, were compared with 16 manic-episode patients who were to be treated with ECT but not valproate. The two groups were compared on the basis of electroencephalography-registered seizure duration and the propofol dosage required to induce anesthesia.

Results: Valproate, compared with no valproate treatment, results in a decrease in the propofol dose required to induce anesthesia. In the valproate group of study participants, seizure duration was significantly shorter than in the valproate-free group.

Conclusion: The results suggest that valproate reduces the dose of propofol required for anesthesia during ECT treatment in patients with bipolar affective disorder manic episodes. Although propofol is a safe and efficacious anesthetic for ECT treatment, lower doses of propofol should be used to induce anesthesia for patients under valproate treatment. When the clinician needs to prolong seizure duration in patients treated with valproate, interruption of the valproate treatment or an anesthetic agent other than propofol should be considered.

Keywords: bipolar affective disorder, ECT, anticonvulsant, mood stabilizer

\section{Introduction}

Electroconvulsive therapy (ECT) is a treatment based on the creation of generalized convulsions through electrical stimulation of the brain and is applied in cases that do not respond sufficiently to psychopharmacological treatment approaches. It has been reported that convulsions lasting less than 15 seconds and seizure activity, monitored on electroencephalography (EEG), of less than 25 seconds duration have inadequate therapeutic efficacy. ${ }^{1}$ However, seizure duration alone is not sufficient for the therapeutic effectiveness of ECT. ${ }^{2}$

Today, ECT treatments are performed with anesthesia and muscle relaxants. Most of the anesthetic agents used for general anesthesia have been used in ECT applications. Mostly short-acting intravenous anesthetic agents are used. ${ }^{3,4}$ The impact of different anesthetic agents on seizure duration varies, ${ }^{5}$ so it can be assumed that the choice 
of anesthetic agent might influence both the main and side effects of ECT.

"Propofol" (2,6-di-isopropylphenol) is a nonbarbituratestructured anesthetic agent that is metabolized remarkably fast, with $80 \%$ transformed into metabolites in 30 minutes. $^{6}$ Its metabolites have pharmacological activity. Ninety-eight percent of the products are excreted in the urine, and the remaining $2 \%$ in feces. ${ }^{7}$ Propofol has been shown to exert significant anticonvulsant activity against pentetrazol- and penicillin G-induced seizures. ${ }^{8}$ In recent studies during ECT, propofol has been shown to possess significant seizureshortening properties. ${ }^{3,4,9,10}$

"Valproate" is a mood stabilizer used mainly in bipolar affective disorder treatment. It is reported that valproate, being an anticonvulsant, raises the seizure threshold, thus decreases the efficacy of ECT treatment. ${ }^{11}$ In a review, Sienaert et al suggested that valproate treatment can continue during ECT treatment for epileptic patients. ${ }^{12}$ If valproate is used as a mood stabilizer, it is recommended for use after ECT treatment. If it is decided that valproate treatment is to be continued, the dose should be reduced by $40 \%$, and the morning dose should not be taken before ECT. ${ }^{12}$ The literature on the use of anesthetic agents with combination ECT and valproate treatment is limited. Sienaert et al reported that in a bipolar affective disorder-diagnosed patient, valproate was added to the treatment protocol during ECT. After changing the anesthetic agent (remifentanil added to a lower dose of methohexital, or etomidate instead of methohexital) due to insufficient seizure duration despite maximum stimulation, sufficient seizure formation was reported despite unchanged valproate dose. ${ }^{13}$ Virupaksha et al evaluated 201 consecutive patients who received bilateral ECT. ${ }^{14}$ Those on concomitant antiepileptic medication had higher seizure threshold and shorter duration of seizures than those who were not on antiepileptic medication. They found the clinical outcome to be similar at the end of the ECT course with or without concomitant antiepileptic medication, although those with concomitant antiepileptic medication required a greater number of ECT sessions than those without antiepileptic medications.

The aim of the study reported here is to investigate the effect of valproate treatment on the dose of propofol required for anesthesia and seizure duration on ECT.

\section{Methods}

This study was performed after approval by the local ethics committee of Uskudar University and informed consent obtained from all patients. The study group was composed of 17 patients with a diagnosis of bipolar affective disorder manic episodes, receiving valproate treatment and ECT in Neuropsychiatry Istanbul Hospital, Istanbul, Turkey between December 2010 and May 2013. The control group consisted of 16 patients with diagnosis of bipolar affective disorder manic episodes who were receiving ECT but not valproate. Prior to the ECT sessions, to determine patients' plasma levels of valproate, $5 \mathrm{~mL}$ samples of venous blood were taken. Valproate plasma levels were analyzed with liquid chromatography-mass spectrometry.

All ECT applications were administered through briefpulse bidirectional square-wave machine, (System IV Thymatron ${ }^{\circledR}$ ECT device, Somatics, LLC, Lake Bluff, IL, USA). All of the patients received bilateral bi-temporal ECT. For the formation of an effective convulsion, 20-60 joule current was applied. ECT-induced seizure duration was monitored with EEG using a MECTA spECTrum device (MECTA Corporation, Portland, OR, USA). ECT was applied three times a week after 12-hour fasting and psychoactive medications stopped for 12 hours before ECT. Age-based method was used as ECT stimulus dosing protocol. ${ }^{15}$ In age-based dosing, the initial dose (in \% Energy) is typically one-half age for bilateral placements and full age for right unilateral. The $\%$ energy refers to the percent of the ECT device maximum charge, $504 \mathrm{mC}$ at $900 \mathrm{~mA}$ current.

SPSS software (version 15.0.1; SPSS Inc., Chicago, IL, USA) was used for statistical analysis. All data are given as mean \pm standard deviation and percentage value. In comparing both group means, the Wilcoxon signed-rank test, a nonparametric alternative to a paired sample Student's $t$-test, was used. The Wilcoxon test compares data from paired (or matched) samples. In all assessments, 0.05 was used as the level of statistical significance.

\section{Sedation protocol}

All patients were administered propofol infusion until the bispectral index (BIS) sensor value reached 60. The BIS sensor probe was placed on the patient's forehead and connected to the BIS monitor to evaluate the sedation level. For both groups, the dose of propofol was recorded. After the BIS value decreased below $60,1 \mathrm{mg} / \mathrm{kg}$ succinylcholine was administered intravenously to provide muscle relaxation.

\section{Results}

The study group comprised 17 patients with whom oral valproate was used during ECT; of these, $52.9 \%(n=9)$ were male and $47.1 \%(n=8)$ female, with an average age of 32.6 years. The control group consisted of 16 with whom valproate 
was not used during ECT; $56.3 \%(n=9)$ of the patients in this group were male and $43.8 \%(n=7)$ were female, with an average age of 33.1 years. Sociodemographic data for the groups are summarized in Table 1. The two groups did not differ significantly in terms of age, sex, or body mass index. Concurrent psychotropics during ECT also did not reveal any differences between the two groups that were statistically significant, with 16 patients in the valproate group (typical neuroleptics, $n=5$; atypical neuroleptics, $n=11$ ) and 15 patients in the valproate-free group (typical neuroleptics, $\mathrm{n}=6$; atypical neuroleptics, $\mathrm{n}=10$ ). Other drugs remained unchanged during the course of treatment. None of the patients were on a benzodiazepine or other mood stabilizer such as lithium or carbamazepine.

In the valproate group, the mean propofol dose used in the first, second, third, fourth, and fifth ECT session was $1.06,1.15,1.08,1.05$, and $1.06 \mathrm{mg} / \mathrm{kg}$, respectively. The average plasma valproate level measured before the first, second, third, fourth, and fifth ECT session was 22.4, 26.5, $22,4,20.0$, and $24.5 \mathrm{mcg} / \mathrm{mL}$, respectively. The mean seizure duration was measured as 29.7, 27.4, 24.1, 30.2, and 26.0 seconds for the first, second, third, fourth, and fifth ECT session, respectively, while in the valproate-free control group, the mean propofol dose used in the first, second, third, fourth, and fifth ECT session was 1.50, 1.55, 1.50, 1.60, and $1.63 \mathrm{mg} / \mathrm{kg}$, respectively. The mean seizure duration was measured as 44.5, 35.2, 54.0, 43.5, and 51.7 seconds for the first, second, third, fourth, and fifth ECT session, respectively.

The Wilcoxon signed-rank test was used to compare the groups in terms of the mean propofol dose. There was $5 \%$ significance for asymptotic significance (two-tailed) between the two groups $P=0.05$. For the first session of ECT, the difference in mean propofol dose had a level of significance of 0.03. For the second, third, fourth, and fifth ECT sessions, the levels of significant difference in mean propofol dose between the valproate group and valproate-free group were $0.01,0.03,0.01$ and 0.01 , respectively.

Table I Sociodemographic characteristics

\begin{tabular}{lll}
\hline Characteristic & $\begin{array}{l}\text { Valproate } \\
\text { group }\end{array}$ & $\begin{array}{l}\text { Valproate-free } \\
\text { group }\end{array}$ \\
\hline Age, years \pm SD & $32.6 \pm 6.5$ & $33.1 \pm 5.6$ \\
$\begin{array}{l}\text { Disease duration, years } \pm \text { SD } \\
\text { Sex, n (\%) }\end{array}$ & $3.8 \pm 1.5$ & $3.9 \pm 1.7$ \\
$\quad$ Male & $9(52.9)$ & $9(56.3)$ \\
Female & $8(47.1)$ & $7(43.8)$ \\
BMI $\left(\mathrm{kg} / \mathrm{m}^{2}\right)($ mean $\pm \mathrm{SD})$ & $22.9 \pm 3.13$ & $22.18 \pm 3.12$ \\
\hline
\end{tabular}

Abbreviations: BMI, body mass index; SD, standard deviation.
ECT seizure duration and propofol doses for both groups are summarized in Table 2.

When the two groups were compared in terms of ECT seizure duration, for the first ECT session there was a significant difference ( $P=0.031)$, while for the second session there was no significant difference $(P=0.069)$ between the two groups. For the third, fourth, and fifth sessions, seizure durations were significantly different between the valproate and valproate-free groups.

\section{Discussion}

In this study, the effect of valproate on propofol dose and seizure duration during ECT was investigated. To the best of our knowledge, there has been no other study investigating the interaction between propofol and valproate during ECT application.

In both the valproate and valproate-free groups, there was no significant difference detected in terms of age, sex, weight, or duration of disease. In anesthetized ECT treatment with propofol, a statistically significant decrease in the dose of propofol required for sedation was detected in the valproate group when compared with the control group. This finding is consistent with the literature.

In an in vitro study, valproate was reported to inhibit cytochrome P450 2C9 which has a role in the metabolism of propofol, ${ }^{16}$ while in another study, valproate was reported to inhibit UDP-glucuronosyltransferase 1A9 enzyme system, which is essential in the metabolism of propofol. This might result in a decrease in the dose required for sedation. ${ }^{17}$ In a study performed with epileptic patients, it was reported that valproate-using patients required lower doses of propofol for sedation in dental treatment than those not receiving valproate. ${ }^{18}$ Additionally, valproate increases the rate of proteinunbound free propofol in human serum, which results in an increase in sedative effect due to the free propofol. ${ }^{19}$

In terms of pharmacodynamics, both valproate and propofol act on gamma-aminobutyric acid (GABA) receptors. The reason for the lower dose of propofol required for sedation in the valproate group compared with the control group in this study may be due to this synergic effect. ${ }^{20}$ In a recent study, it was reported that continuing the administration of sodium valproate neither adversely affected nor enhanced cognitive impairment or seizure duration during ECT in patients suffering from manic episodes. ${ }^{21}$ In the present study, we found the seizure duration significantly low in the valproate group, when compared with the control group. Although there were no seizures of less than 20 seconds, seizure duration in the valproate group was shorter than in the control group. 
Table 2 Propofol dose, valproate plasma levels, and seizure durations of patients

\begin{tabular}{|c|c|c|c|c|c|c|}
\hline Parameter & Patients & Ist session & 2nd session & 3rd session & 4th session & 5th session \\
\hline \multirow[t]{3}{*}{ Propofol dosage $(\mathrm{mg} / \mathrm{kg})$} & Valproate using & 1.06 & 1.15 & 1.08 & 1.05 & 1.06 \\
\hline & Valproate free & 1.50 & 1.55 & 1.50 & 1.60 & 1.63 \\
\hline & $P$ & 0.03 & 0.01 & 0.03 & 0.01 & 0.01 \\
\hline \multirow[t]{3}{*}{ Seizure duration (seconds) } & Valproate using & 29.7 & 27.4 & 24.1 & 30.2 & 26.0 \\
\hline & Valproate free & 44.5 & 35.2 & 54.0 & 43.5 & 51.7 \\
\hline & $P$ & 0.031 & 0.069 & 0.002 & 0.021 & 0.002 \\
\hline Therapeutic range: & & 22.4 & 26.5 & 22.4 & 20.0 & 24.5 \\
\hline $50-100 \mathrm{mcg} / \mathrm{mL}$ & & & & & & \\
\hline
\end{tabular}

Propofol is potentially a strong anticonvulsant and has been reported to shorten the duration of seizures in ECT. ${ }^{9,22,23}$ Propofol has also been reported to block $\mathrm{Na}^{+}$and $\mathrm{Ca}^{2+}$ channels, nicotinic receptors, the N-methyl-D-aspartate receptor, and activate the rectifying outward $\mathrm{K}^{+}$currents. ${ }^{24} \mathrm{In}$ this respect, the mechanisms of propofol's activity resemble to some extent those of carbamazepine, and this effect may result in propofol's action on seizure duration. However, studies have reported that the reduction in seizure duration depended on the dose of propofol. ${ }^{25,26}$ In a study comparing ECT parameters and response to ECT in patients anesthetized with methohexitone, propofol, or etomidate, the mean seizure duration was found to be lowest for propofol, but the choice of anesthetic did not seem to influence therapeutic response to ECT. ${ }^{5}$

Valproate's mechanism of action is associated with its ability to suspend recovery from the inactivation of $\mathrm{Na}^{+}$ channels. ${ }^{27}$ In research, combinations of valproate and propofol were found to lead to synergistic interactions. ${ }^{28}$ In the present study, although the valproate-free group had higher doses of propofol, seizure duration was found to be higher than in the valproate group. On the other hand, valproate also influences seizure duration. ${ }^{29}$ The lower seizure duration in the valproate group was considered related to the drug's anticonvulsant effect.

The currently available literature indicates that ECT can be safely and effectively administered to patients treated with various anticonvulsants. No serious adverse effects or complications have been reported. ${ }^{12}$ However, anticonvulsants may alter seizure expression and seizure duration and, therefore, diminish the therapeutic effectiveness of treatment. Zarate et al reported the case of 65 -year-old man with the diagnosis of bipolar affective disorder who was treated with ECT for depression while he was on valproate treatment. ${ }^{30}$ With a valproate dose of $1000 \mathrm{mg} /$ day, ECT was not able to induce a seizure in four consecutive trials. When the dose of valproate was reduced to $750 \mathrm{mg} /$ day, there was no further difficulty in the elicitation of seizures.
The American Psychological Association advises against the combination of anticonvulsant agents and ECT, unless anticonvulsants are used for antiepileptic purposes. ${ }^{31}$ In contrast, British practice recommendations state that anticonvulsants can be continued during a course of ECT, even if they are used as a mood stabilizer. ${ }^{32}$ Valproate can be continued during a course of ECT when it is planned to continue mood-stabilizer treatment with valproate. It might be useful to start valproate before the end of the ECT course to obtain a therapeutic plasma level of the drug. However, administering valproate concurrently with ECT may alter seizure duration and increase the risk of subthreshold seizures and necessity of restimulations, leading to an increased risk of bradycardia and postictal agitation. The combination of ECT and anticonvulsants may be considered in patients for whom prophylaxis with anticonvulsant drugs is planned. In this study, we decided to continue valproate as a mood stabilizer after finishing the ECT course, so valproate doses were tapered off before the ECT course was started and plasma levels were maintained in the $20-30 \mathrm{mcg} / \mathrm{mL}$ range.

In clinical practice, the measurement of seizure duration is hypothesized to be a useful surrogate marker of therapeutic effectiveness. ${ }^{33}$ In their historical research, Cronholm and Ottosson examined the effect of lidocaine pretreatment in ECT and reported that when seizures were shortened due to lidocaine, the depression-relieving effect of ECT was decreased..$^{34}$ In a recent research study, it was reported that seizure durations may have some predictive value, in addition to other markers of EEG morphology. ${ }^{35}$ There have also been contrary opinions, suggesting that seizure duration alone should not serve as a marker of the adequacy of treatment - there are complex relations between stimulus dosing and seizure duration, with the possibility that substantially suprathreshold stimulation may result in shorter durations, particularly early in the treatment course. . $^{36,37}$

The application of anesthetic for ECT can be tailored to patients. Propofol causes fewer hemodynamic changes than 
etomidate or thiopentone,$^{38}$ so may be useful in patients with cardiac disease. Further, propofol may be the anesthetic of choice in adolescents and young adults as well as in patients who have prolonged seizure. ${ }^{39}$

\section{Limitations}

This was a retrospective study without patient randomization to the valproate or valproate-free groups. Since the sample size was small, the capacity of the study to demonstrate the differences between the two groups may have been reduced. Although it is limited by a relatively small sample size, the significance of the results highlights the need for further investigation in a significant clinical debate: the effect of anesthetic agents and valproate on ECT, and the interaction between valproate and the concomitant administration of an anesthetic agent. Although the sample size was small, a constant stimulus dose technique was used during the ECT of a homogeneous group. Only patients diagnosed with bipolar affective disorder manic episodes were included, and results were based on five sessions. The study group was not large but was similar to those of other retrospective studies, and larger than those of previous studies with a crossover design. A well-designed prospective study would largely overcome the sample-size limitation and could provide more convincing evidence.

In future research, as patients on concomitant antiepileptic medication receive higher electrical charges, it would be important to assess if this is associated with greater cognitive adverse effects. The American Psychological Association task force recommends reducing the dose or stopping the medication completely if a patient is on antiepileptic drugs for mood stabilization. ${ }^{31}$ If antiepileptic drugs are for the treatment of epilepsy, then reducing the dose or skipping the morning dose is recommended. ${ }^{31}$ Very little empirical evidence is available to support these guidelines. ${ }^{2}$ This underscores the need for systematic studies of these aspects.

\section{Conclusion}

The normal dose of propofol may be excessive for patients receiving oral valproate treatment and may induce complications or delay recovery from anesthesia in ECT. Although the required propofol dose was significantly reduced in ECTreceiving valproate-using patients, the use of another anesthetic agent is recommended to prevent shorter seizure duration.

\section{Author contributions}

All authors participated in the design of the study and analysis. This article has been read and revised by all authors.
All authors read and approved the final manuscript for publication.

\section{Disclosure}

The authors report no conflicts of interest in this work.

\section{References}

1. Scott AI. Electroconvulsive therapy, practice and evidence. $\mathrm{Br} J$ Psychiatry. 2010;196(3):171-172.

2. Thirthalli J, Prasad MK, Gangadhar BN. Electroconvulsive therapy (ECT) in bipolar disorder: a narrative review of literature. Asian $J$ Psychiatry. 2012;5(1):11-17.

3. Kellner CH, Bryson EO. Electroconvulsive therapy anesthesia technique: minimalist versus maximally managed. J ECT. 2013;29(3):153-155.

4. Grundmann U, Schneider SO. Narkose zur Elektrokrampftherapie [Anesthesia for electroconvulsive therapy]. Der Anaesthesist. 2013;62(4):311-322. German.

5. Eranti SV, Mogg AJ, Pluck GC, Landau S, McLoughlin DM. Methohexitone, propofol and etomidate in electroconvulsive therapy for depression: a naturalistic comparison study. J Affect Disord. 2009;113(1-2):165-171.

6. de la Fuente NF, Puga VA, Cortínez LI, Muñoz HR. The effective effect-site propofol concentration for induction in morbidly obese patients using total body weight with a new pharmacokinetic model. Anesth Analg. 2013;117(1):283-284.

7. Daria U, Kumar V. Comparison of thiopentone and propofol as better anaesthetic agent for modified electroconvulsive therapy. Asian Journal of Pharmaceutical and Clinical Research. 2012;5(2):227-230.

8. De Riu PL, Petruzzi V, Testa C, et al. Propofol anticonvulsant activity in experimental epileptic status. Br J Anaesth. 1992;69(2):177-181.

9. Küçük A, Karababa F, Yüce HH, Yalçin S. Effects of propofol and ketamine as combined anesthesia for electroconvulsive therapy in patients with depressive disorder: a perspective from anesthesiologists. J ECT. 2013;29(3):249.

10. Algül A, Sen H, Ates MA, et al. Propofol versus propofolremifentanil combination anaesthesia in electroconvulsive therapy: Effects on seizure duration and hemodynamics. Klinik Psikofarmakoloji Bülteni [Bulletin of clinical psychopharmacology]. 2009;19(1):29-38.

11. Petrides G, Braga RJ, Fink M, et al; CORE (Consortium for Research in ECT) Group. Seizure threshold in a large sample: implications for stimulus dosing strategies in bilateral electroconvulsive therapy: a report from CORE. J ECT. 2009;25(4):232-237.

12. Sienaert P, Peuskens J. Anticonvulsants during electroconvulsive therapy: review and recommendations. J ECT. 2007;23(2):120-123.

13. Sienaert P, Bouckaert F, Hagon A, Hagon B, Peuskens J. Short seizures in continuation electroconvulsive therapy: an indication for remifentanil anesthesia? JECT. 2004;20(2):130-131.

14. Virupaksha HS, Shashidhara B, Thirthalli J, Kumar CN, Gangadhar BN. Comparison of electroconvulsive therapy (ECT) with or without antiepileptic drugs in bipolar disorder. J Affect Disord. 2010;127(1-3): 66-70.

15. Fink M. Energy dosing in ECT: threshold stimulation or formula? Convuls Ther. 1997;13(1):4-6.

16. Wen X, Wang JS, Kivistö KT, Neuvonen PJ, Backman JT. In vitro evaluation of valproic acid as an inhibitor of human cytochrome P450 isoforms: preferential inhibition of cytochrome P450 2C9 (CYP2C9). Br J Clin Pharmacol. 2001;52(5):547-553.

17. Ethell BT, Anderson GD, Burchell B. The effect of valproic acid on drug and steroid glucuronidation by expressed human UDP-glucuronosyltransferases. Biochem Pharmacol. 2003;65(9):1441-1449.

18. Ishii M, Higuchi H, Maeda S, Tomoyasu Y, Egusa M, Miyawaki T. The influence of oral VPA on the required dose of propofol for sedation during dental treatment in patients with mental retardation: a prospective observer-blinded cohort study. Epilepsia. 2012;53(1):e13-e16. 
19. Ishii M, Sakurai S, Higuchi H, Maeda S, Tomoyasu Y, Miyawaki T. Valproate increases the rate of protein-unbound free propofol in human serum. Abstract A990. American Society of Anesthesiologists Annual Meeting, October 2012, Washington, DC, USA

20. Owens MJ, Nemeroff CB. Pharmacology of valproate. Psychopharmacol Bull. 2003;37(Supp1 2):17-24.

21. Haghighi M, Bajoghli H, Bigdelou G, Jahangard L, Holsboer-Trachsler E, Brand S. Assessment of cognitive impairments and seizure characteristics in electroconvulsive therapy with and without sodium valproate in manic patients. Neuropsychobiology. 2013;67(1):14-24.

22. Wang X, Chen Y, Zhou X, Liu F, Zhang T, Zhang C. Effects of propofol and ketamine as combined anesthesia for electroconvulsive therapy in patients with depressive disorder. J ECT. 2012;28(2):128-132.

23. Kumar A, Sharma DK, Mani R. A comparison of propofol and thiopentone for electroconvulsive therapy. J Anaesthesiol Clin Pharmacol. 2012;28(3):353-357.

24. Borowicz KK, Łuszczki J, Czuczwar SJ. Interactions between nonbarbiturate injectable anesthetics and conventional antiepileptic drugs in the maximal electroshock test in mice - an isobolographic analysis. Eur Neuropsychopharmacol. 2004;14(2):163-172.

25. Imashuku Y, Kanemoto K, Senda M, Matsubara M. Relationship between blood levels of propofol and recovery of memory in electroconvulsive therapy. Psychiatry and Clinical Neurosciences. Epub December 8, 2013.

26. Anand S, Thirthalli J, Gupta A, et al. Anesthesia during electroconvulsive therapy: importance of dosage. JECT. 2010;26(2):145.

27. Deckers CL, Czuczwar SJ, Hekster YA, et al. Selection of antiepileptic drug polytherapy based on mechanisms of action: the evidence reviewed. Epilepsia. 2000;41(11):1364-1374.

28. Borowicz KK, Czuczwar SJ. Effects of etomidate, ketamine or propofol, and their combinations with conventional antiepileptic drugs on amygdala-kindled convulsions in rats. Neuropharmacology. 2003;45(3):315-324.

29. Jahangard L, Haghighi M, Bigdelou G, Bajoghli H, Brand S. Comparing efficacy of ECT with and without concurrent sodium valproate therapy in manic patients. $J E C T$. 2012;28(2):118-123.
30. Zarate CA Jr, Tohen M, Baraibar G. Combined valproate or carbamazepine and electroconvulsive therapy. Ann Clin Psychiatry. 1997;9(1):19-25.

31. American Psychiatric Association. The Practice of ECT: Recommendations for Treatment, Training, and Privileging. 2nd ed. Washington DC: American Psychiatric Press; 2001.

32. Scott AI, editor. The ECT Handbook: The Third Report of the Royal College of Psychiatrists'Special Committee on ECT. 2nd ed. Council Report CR128. London: Royal College of Psychiatrists; 2005.

33. Rasmussen K. The Practice of Electroconvulsive Therapy: Recommendations for Treatment, Training, and Privileging (Second Edition). J ECT. 2002;18(1):58-59.

34. Cronholm B, Ottosson JO. Experimental studies of the therapeutic action of electroconvulsive therapy in endogenous depression. The role of the electrical stimulation and of the seizure studied by variation of stimulus intensity and modification by lidocaine of seizure discharge. Acta Psychiatr Scand Suppl. 1960;35(145):69-101.

35. Kimball JN, Rosenquist PB, Dunn A, McCall V. Prediction of antidepressant response in both $2.25 x$ threshold RUL and fixed high dose RUL ECT. J Affect Disord. 2009;112(1-3):85-91.

36. Sackeim HA, Devanand DP, Prudic J. Stimulus intensity, seizure threshold, and seizure duration: impact on the efficacy and safety of electroconvulsive therapy. Psychiatr Clin North Am. 1991;14(4): 803-843.

37. Kales H, Raz J, Tandon R, et al. Relationship of seizure duration to antidepressant efficacy in electroconvulsive therapy. Psychol Med. 1997;27(6):1373-1380.

38. Kadoi Y, Saito S, Ide M, et al. The comparative effects of propofol versus thiopentone on left ventricular function during electroconvulsive therapy. Anaesth Intensive Care. 2003;31(2):172-175.

39. Bailine SH, Petrides G, Doft M, Lui G. Indications for the use of propofol in electroconvulsive therapy. J ECT. 2003;19(3): 129-132.
Neuropsychiatric Disease and Treatment

\section{Publish your work in this journal}

Neuropsychiatric Disease and Treatment is an international, peerreviewed journal of clinical therapeutics and pharmacology focusing on concise rapid reporting of clinical or pre-clinical studies on a range of neuropsychiatric and neurological disorders. This journal is indexed on PubMed Central, the 'PsycINFO' database and CAS.

\section{Dovepress}

The manuscript management system is completely online and includes a very quick and fair peer-review system, which is all easy to use. Visit http://www.dovepress.com/testimonials.php to read real quotes from published authors. 